\title{
The Effect of Education on the Assessment of Optic Nerve Head Photographs for the Glaucoma Diagnosis
}

\author{
Sabina Andersson ${ }^{1 *}$, Anders Heijl', Andreas G Boehm²,3 and Boel Bengtsson ${ }^{1}$
}

\begin{abstract}
Background: To evaluate the effect of one lesson of continuing medical education (CME) of subjective assessment of optic nerve head appearance on sensitivity and specificity for the diagnosis of glaucoma.

Methods: Ophthalmologists and residents in ophthalmology attending an international glaucoma meeting arranged at Malmö University Hospital, Malmö, Sweden, were asked to grade optic nerve head (ONH) photographs of healthy and glaucomatous subjects at two sessions separated by a lecture on glaucoma diagnosis by ONH assessment. Each grader had access to an individual portfolio of $50 \mathrm{ONH}$ photographs randomly selected from a web-based data bank including ONH photographs of 73 glaucoma patients and 123 healthy subjects. The individual portfolio of photographs was graded before and after the lecture, but in different randomized order.
\end{abstract}

Results: Ninety-six doctors, $91 \%$ of all attending the meeting, completed both assessment sessions. The number of correct classifications increased from 69 to $72 \%$ on the average. Diagnostic sensitivity increased significantly ( $p<$ 0.0001 ) from $70 \%$ to $80 \%$, and the number of photographs classified as uncertain decreased significantly ( $<<$ 0.0001 ) from $22 \%$ to $13 \%$. Specificity remained at $68 \%$, and intra-grader agreement decreased.

Conclusion: CME had only a small effect on the assessment of ONH for the glaucoma diagnosis. Sensitivity increased and the amount of uncertain classifications decreased, while specificity was unchanged.

\section{Background}

In clinical practice assessment of glaucomatous changes of the optic nerve head $(\mathrm{ONH})$ may be the first step to detect glaucoma. Inspection of the posterior pole by e.g. ophthalmoscopy is a routine examination in most eye clinics. A suspect $\mathrm{ONH}$ appearance often directly leads to further examinations including perimetry and tonometry, or to referral of the patient. $\mathrm{ONH}$ assessment is sometimes a difficult task, particularly at early stages of glaucoma, requiring careful observation and knowledge about variability of optic disc appearance among healthy subjects and the characteristics of glaucomatous damage. Large and pale excavations at advanced stages of glaucoma have been recognized since the ophthalmoscope was introduced in the 1850's. Cup to disc ratios [1] was an attempt to quantify the excavation of $\mathrm{ONH}$,

\footnotetext{
* Correspondence: sabina.andersson@med.lu.se

'Department of Clinical Sciences, Ophthalmology, Malmö, Lund University, Sweden

Full list of author information is available at the end of the article
}

and a number of signs typical for glaucoma have been described, e.g., saucerization of the disc [2], thinning of the neural rim [3], focal notching [4]. Disc hemorrhages, first described by Bjerrum in 1889 [5] are now considered a relatively hard sign of glaucoma. The ISNT rule suggested by Jonas and co-workers 1988 [6] compares the width of the neural rim in the interior, superior, nasal and temporal parts of the $\mathrm{ONH}$. The size of the $\mathrm{ONH}$ is important for detection of glaucoma $[7,8]$. Glaucomatous eyes having small ONHs are more likely to be classified as normal than glaucomatous eyes with normal or large ONHs. On the contrary, healthy eyes with large OHNs are more likely to be classified as glaucomatous than healthy eyes with normal or small ONHs $[9,10]$.

During the last two decades new computerized image techniques measuring and analyzing ONHs were developed. However, these image techniques are typically applied on patients already having a diagnosis of glaucoma or suspect glaucoma, and are not standard
C Biomed Central

(c) 2011 Andersson et al; licensee BioMed Central Ltd. This is an Open Access article distributed under the terms of the Creative Commons Attribution License (http://creativecommons.org/licenses/by/2.0), which permits unrestricted use, distribution, and reproduction in any medium, provided the original work is properly cited. 
examinations in patients visiting eye departments/clinics for reasons other than suspect glaucoma or glaucoma. Therefore, subjective evaluation of the $\mathrm{ONH}$, by e.g. ophthalmoscopy, is still important and often remains the first step when diagnosing previously undetected glaucoma.

A number of earlier studies have reported diagnostic accuracy of subjective assessment of the ONH [11-17], but to our knowledge no studies have reported on the effect of continuing medical education (CME) on diagnostic accuracy of subjective optic disc assessment of residents in ophthalmology or of ophthalmologists.

The aim of our study was to evaluate the effect of one hour of CME of ophthalmologists on the subjective grading of $\mathrm{ONH}$ photographs from glaucoma patients and healthy individuals.

\section{Methods}

In conjunction with an international glaucoma meeting at Malmö University Hospital, Malmö, Sweden in March 2008, attending doctors were asked to grade $\mathrm{ONH}$ photographs using a web-based protocol at two different sessions. The two sessions were separated b y a lecture in glaucoma diagnosis by $\mathrm{ONH}$ assessment. Participation was voluntary and the first assessment was made before the start of the meeting, while the second assessment was performed after the lecture. No time limits for the assessments were given. The participants were each asked to classify $56 \mathrm{ONH}$ photographs into one of three different categories: glaucomatous, normal or uncertain. Fifty photographs were unique and 6 duplicates. They were also asked to report whether they considered themselves to be a glaucoma expert, general ophthalmologist with special interest in glaucoma, general ophthalmologist, or ophthalmologist with another subspecialty. The participants were also asked to report their experience in glaucoma by choosing one of the following alternatives; lack of experience, less experienced, experienced or very experienced, and to report the average number of glaucoma patients seen per month.

The research project followed the tenets of the Declaration of Helsinki and was approved by the regional ethical review board in Lund, Sweden, vetting the ethics of research involving humans.

\section{Photographs - glaucoma patients and healthy subjects} $\mathrm{ONH}$ photographs from glaucoma patients and healthy subjects were retrieved from an existing database. The database has been described previously $[18,19]$. All glaucoma subjects were patients at the Department of Ophthalmology, Malmö University Hospital. All had a diagnosis of glaucoma with reproducible visual field defects and the Glaucoma Hemifield Test outside normal limits on standard automated perimetry using the 30-2
Full Threshold program of the Humphrey Field Analyzer (Carl Zeiss Meditec, Dublin, Calif, USA). To be included we required that the interval between the visual field test and photograph should be less than 12 months, and that the image quality was good enough to enable a fair evaluation. Photographs with obvious artifacts, e.g., the shutter half way down or prominent reflections, were excluded. One eye per patient, the one with the best perimetric Mean Deviation (MD) value, was selected. A total of 73 photographs from 73 glaucoma patients were included. Mean age for these patients was 70 years, ranging from 50 to 87 and the mean MD was $-7.39 \mathrm{~dB}$, ranging from -19.56 to $+1.01 \mathrm{~dB}$.

The healthy subjects were randomly selected individuals living in the city of Malmö, Sweden [18]. At the time for the data collection all supposedly healthy subjects underwent a thorough ophthalmic examination including determination of refraction and visual acuity, Goldmann applanation tonometry, slitlamp examination and recording of ophthalmic and general medical history. Inclusion criteria were corrected visual acuity $\geq$ 0.8 , intraocular pressure $<22 \mathrm{mmHg}$. Exclusion criteria were history of serious eye trauma or surgery, previous or current serious eye disease or any neurological disease. Again we excluded $\mathrm{ONH}$ photographs with poor quality or with obvious artifacts. To match the age of the glaucoma patients all subjects younger than 50 years of age at the time for the data collection were excluded. One eye per subject was randomly chosen and a total of 128 normal eyes were included. The mean age of the healthy subjects was 66 years, ranging from 51 to 79 .

All photographs were obtained using the same fundus camera, a Carl Zeiss (Model 60 306, Oberkochen, West Germany) with standard settings (aperture 5.5, flash strength 120-240 Ws), using Kodachrome 64 slide film. The photographs were digitized using Nikon Super Coolscan 4000 ED diapositive scanner with the highest resolution of 4000 Dots Per Inch (dpi). The size was thereafter changed to $1400 \times 1024$ pixels with a resolution of 72 dpi to create a database that can be accessed through a web interface. This web-based database included the $201 \mathrm{ONH}$ photographs. When logging in to the database a random subset of 50 photographs was automatically selected, and a unique mix of photographs was created for each grader. To be able to test intra-grader agreement, $6 \mathrm{ONH}$ photographs randomly selected in each subset of 50 photographs were duplicated, thus creating an individual mix of $56 \mathrm{ONH}$ photographs. Each grader then classified the same 56 photographs before and after the lecture, but the photographs were sorted in different randomized orders. The median number of photographs from glaucoma subjects was 19 (ranging from 12 to 24), and 31 from healthy individuals (ranging from 26 to 38 ). 


\section{The lecture}

The lecture in $\mathrm{ONH}$ assessment for glaucoma diagnosis was performed by one of the authors (AGB). It was a one hour lecture based on Dr. Remo Susanna's course "How to assess the optic nerve head and the retinal nerve fiber layer in glaucoma", with definition of five rules to detect glaucoma [20]. The lecture presented a systematic approach to evaluate optic discs with regards to glaucoma detection and focused particularly on the evaluation of optic disc size, neuroretinal rim, retinal nerve fiber layer, parapapillary atrophy and disc hemorrhages. All ONH photographs shown in the lecture were selected by the lecturer and were extracted from an independent database of glaucoma patients and healthy subjects collected at the Department of Ophthalmology, University of Dresden, Dresden, Germany. The lecture was ended with a short training session to use this systematic approach on $15 \mathrm{ONH}$ photographs; nine glaucomatous ONHs, four healthy ONHs, one ONH with drusen and one $\mathrm{ONH}$ with optic pit.

\section{Analyses}

Grader identity was masked in all analyses. Results were calculated for those graders performing assessments both prior to and after the lecture. Diagnostic accuracy was calculated in total as the percentage of correct classification among the $50 \mathrm{ONH}$ photographs of each grader, and as sensitivity and specificity. The "uncertain" classifications were not included in the calculation of diagnostic accuracy. The change between sessions in diagnostic accuracy and number of uncertain classification for the whole group of graders was analyzed by one-sample t-test of differences. Mean values were calculated and reported for each subgroup, however, no comparisons for statistical differences between subgroups were performed since the number of participants was very low in some groups. The intra-grader variability was calculated by kappa statistics and interpreted by the rules suggested by Altman [21]:

No agreement - less than 0

Poor agreement - 0 than 0.20

Fair agreement -0.20 to 0.40

Moderate agreement -0.40 to 0.60

Good agreement - 0.60 to 0.80

Very good agreement -0.80 to 1.00

Change in kappa values was tested by one sample t-test.

\section{Results}

One hundred and forty-one doctors attended the meeting, and 105 participated in the first $\mathrm{ONH}$ assessment prior to the lecture in $\mathrm{ONH}$ assessment. Ninety-six doctors completed both assessment sessions: thus our results are based on those 96 physicians. The largest group, 39\% of all participants, consisted of ophthalmologists with special interest in glaucoma, the second largest, $29 \%$, was general ophthalmologists, $16 \%$ reported themselves to be glaucoma specialist, $3 \%$ other subspecialty and $7 \%$ were residents. The remaining $6 \%$ percent of the 96 participants did not report any group affiliation. The majority, $80 \%$, of the participating doctors stated themselves to be very experienced or experienced in glaucoma care, and $77 \%$ had been active as clinicians for at least 10 years, Table 1 .

After the lecture the number of correct classifications improved significantly ( $\mathrm{p}=0.001$ ) from 68 to $72 \%$. The improvement in sensitivity was notable, from 70 to $80 \%$, $(0<0.0001)$, while specificity remained at the same level at $68 \%$. The number of uncertain classifications decreased significantly ( $\mathrm{p}<0.0001$ ) from 22 to $13 \%$ after the lecture. Figure 1. Eleven percent of the photographs of healthy subjects initially classified as uncertain were correctly classified as normal at the second assessment. A similar number of photographs of glaucomatous eyes, $12 \%$, initially classified as uncertain, were correctly classified as glaucomatous at the second assessment. The number of normal eyes initially erroneously classified as glaucomatous and correctly classified as normal at the second assessment (3\%), was similar to the number of glaucomatous eyes initially erroneously classified as normal but correctly classified as glaucoma at the second assessment (4\%). The difference between normal and glaucomatous eyes was that more initially correctly classified normal eyes were erroneously classified as glaucoma or uncertain in the second assessment (15\%), than were initially correctly classified glaucomatous eyes, which were erroneously classified as normal or uncertain at the second assessment, $4 \%$.

Among the groups sensitivity increased most, 26\%, in the group of three doctors having other subspeciality, and in least, $8 \%$, in the group with glaucoma experts, Table 2. Specificity was almost the same in the first and second assessment session in all subgroups, except for residents, where the specificity decreased with $9 \%$, Table 2 . The number of photographs classified as uncertain decreased in all subgroups. The smallest change was in the group of residents from $17 \%$ to $10 \%$, Table 2 .

Intra-grader agreement, expressed as kappa, was on the average moderate, both before (0.53) and after (0.43)

Table 1 Self reported clinical experience

\begin{tabular}{cclccc}
\hline \multicolumn{2}{c}{$\begin{array}{c}\text { Number of glaucoma } \\
\text { patients seen per month }\end{array}$} & \multicolumn{1}{c}{$\begin{array}{c}\text { Experience of } \\
\text { glaucoma }\end{array}$} & \multicolumn{2}{c}{$\begin{array}{c}\text { Years as } \\
\text { clinician }\end{array}$} \\
\hline$\leq 10$ & $10 \%$ & Lack experience & $1 \%$ & $0-4$ & $8 \%$ \\
$11-50$ & $44 \%$ & Less experience & $19 \%$ & $5-9$ & $15 \%$ \\
$>50$ & $46 \%$ & Experienced & $65 \%$ & $10-14$ & $24 \%$ \\
& & Very experienced & $15 \%$ & $>15$ & $53 \%$ \\
\hline
\end{tabular}




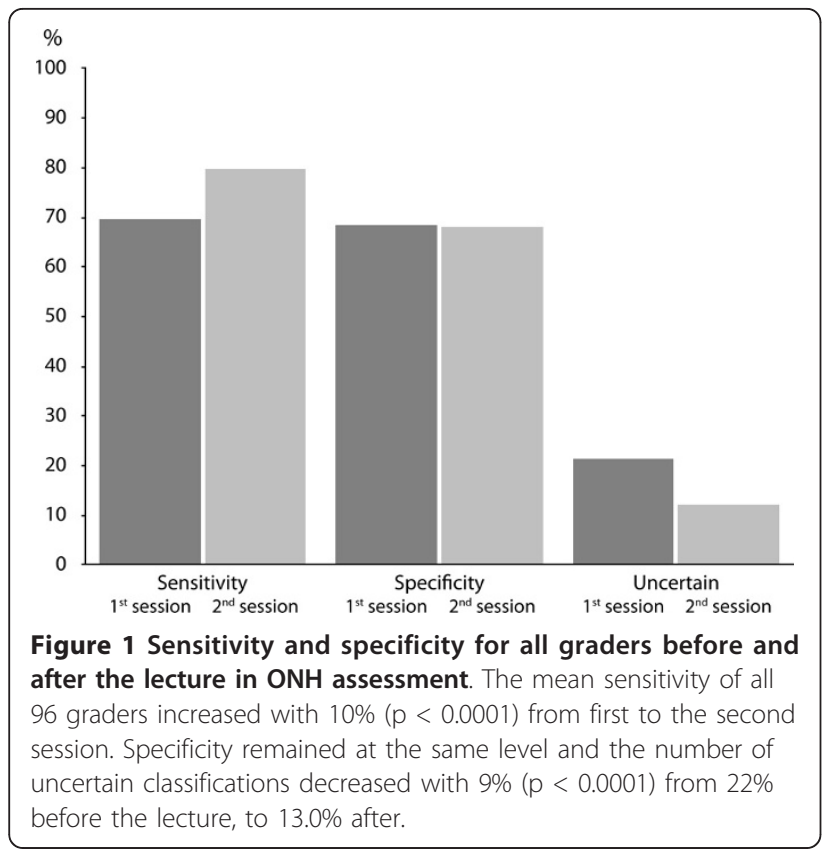

the lecture. The change was significant, $p=0.02$. In the first session 17 graders showed very good agreement, while three graders showed no agreement. In the second session only five graders showed very good agreement and seven graders no agreement.

\section{Discussion}

The effect of re-training of ONH assessment was small, but positive. Sensitivity improved and the number of uncertain classifications decreased, while specificity remained at the same level. The number of physicians in the different subgroups was too small for any statistical analysis, but as expected sensitivity was highest, both before and after the training ( $77 \%$ and $87 \%$ respectively) in the group of glaucoma experts. It may be more surprising that the effect of CME on sensitivity was of similar magnitude, approximately $10 \%$ improvement, in the expert group as in the other subgroups (Table 2) except for those with other subspecialty where sensitivity increased from $55 \%$ to $81 \%$, but this group included 3 ophthalmologists only.

Uncertain classifications in the group with all graders, decreased significantly in number after the training session. A decrease was seen for all the subgroups, and somewhat surprisingly, even the glaucoma experts showed a marked decrease in the amount of uncertain classifications. The move from the uncertain alternative in the first session was almost equally divided to the glaucoma and healthy alternatives in the second session. This improved both sensitivity and specificity, but then the move of correctly classified healthy ONHs in first session to erroneously classifications in the second session was about four times larger than the move of correctly classified glaucomatous $\mathrm{ONHs}$ in the first session to erroneously classifications in the second session, which resulted in improved sensitivity and no change in specificity on the average.

Few articles have described effects of CME on $\mathrm{ONH}$ assessment for the diagnosis of glaucoma. To our knowledge the current study is the first to investigate the effect of CME for the glaucoma diagnosis in ophthalmologists with different experience. This kind of CME is often offered at ophthalmic meetings, with the aim of improving diagnostic performance of the auditorium. Margolis and co-workers reported in 1989 [22] effects of an educational program in $\mathrm{ONH}$ assessment for residents in internal medicine and practicing internists. In this study both sensitivity and specificity improved significantly with 10 to $20 \%$ in the two groups. In the current study sensitivity, but not specificity, improved after the lecture. One reason may be that the short training session at the end of the lecture only included four photographs of healthy ONHs. Perhaps an extended education on normal variability of $\mathrm{ONH}$

Table 2 Average sensitivity, specificity and number of uncertain classifications divided by reported affiliation/ subgroup

\begin{tabular}{|c|c|c|c|c|c|c|c|}
\hline & & \multicolumn{2}{|c|}{ Sensitivity } & \multicolumn{2}{|c|}{ Specificity } & \multicolumn{2}{|c|}{ Uncertain } \\
\hline & & $\begin{array}{c}1^{\text {st }} \\
\text { session }\end{array}$ & $\begin{array}{c}2^{\text {nd }} \\
\text { session }\end{array}$ & $\begin{array}{c}1^{\text {st }} \\
\text { session }\end{array}$ & $\begin{array}{c}2^{\text {nd }} \\
\text { session }\end{array}$ & $\begin{array}{c}1^{\text {st }} \\
\text { session }\end{array}$ & $\begin{array}{c}2^{\text {nd }} \\
\text { session }\end{array}$ \\
\hline All & $n=96$ & $70 \%$ & $80 \%$ & $68 \%$ & $68 \%$ & $22 \%$ & $13 \%$ \\
\hline Glaucoma expert & $\mathrm{n}=15$ & $77 \%$ & $85 \%$ & $67 \%$ & $68 \%$ & $17 \%$ & $6 \%$ \\
\hline $\begin{array}{l}\text { General ophthalmologist } \\
\text { with special interest in } \\
\text { glaucoma }\end{array}$ & $n=37$ & $72 \%$ & $81 \%$ & $72 \%$ & $72 \%$ & $20 \%$ & $12 \%$ \\
\hline General ophthalmologist & $n=28$ & $64 \%$ & $74 \%$ & $67 \%$ & $67 \%$ & $26 \%$ & $16 \%$ \\
\hline Other subspecialist & $n=3$ & $55 \%$ & $81 \%$ & $71 \%$ & $67 \%$ & $31 \%$ & $15 \%$ \\
\hline Resident & $\mathrm{n}=7$ & $72 \%$ & $84 \%$ & $60 \%$ & $51 \%$ & $17 \%$ & $10 \%$ \\
\hline Not specified & $n=6$ & $70 \%$ & $81 \%$ & $70 \%$ & $74 \%$ & $22 \%$ & $12 \%$ \\
\hline
\end{tabular}


appearance would have improved the specificity, similar to that seen on sensitivity. Our ONH photographs came from glaucoma patients with different disease severities from very early glaucoma to those with severe glaucomatous damage. The collection of $\mathrm{ONH}$ photographs of the healthy subjects was performed in a populationbased sample including a wide range of normal $\mathrm{ONH}$ appearances, and not only obviously healthy looking ONHs.

Sheen et al. [23] also reported positive effects of education on disc assessment, but this time performed by medical students. In this study the results parameter was inter-grader agreement, calculated as the standard deviation of cup/disc ratios differences, between students and an expert observer. In the current study we have no result parameter to compare with this inter-grader agreement outcome, but we measured intra-grader agreement before and after the education lecture. Our result was negative, since the intra-grader agreement decreased.

The use of digitized photographs in our study enabled the graders to interpret images without any stress caused by time limits and also strongly facilitated the randomization of images to each grader. Digitized photographs have been shown to be a reasonable alternative and comparable with traditional slide photographs. Stone et al. recently reported that primary digital or scanned optic disc images were suitable substitutes for traditional slide photographs [24]. Within retinal diseases such as diabetic retinopathy and macular degeneration there are several image quality studies comparing digital and digitized images with slide photographs, concluding that there are a close agreement [25-28].

A positive learning effect of teaching could be anticipated, and of course the result depends both on the teacher, the auditorium and the format for the training. In our study the total improvement after the training lesson was significant, however the change was a marginal $4 \%$ only. The lecture format only may not be the optimal way to train ophthalmologist to read $\mathrm{ONH}$ for the diagnosis of glaucoma. A two-way communication, e.g. interactive education, instead of a one-way lecture may possibly yield a somewhat better result.

\section{Conclusions}

Training produced small positive changes in diagnostic performance, also among glaucoma experts. Sensitivity increased significantly, while specificity was unchanged, and the number of uncertain classifications decreased significantly.

\section{Acknowledgements}

Allergan Norden AB funded the work with the web-based database questionnaire. The study was supported by the Swedish Research Council grant K2005-74X-10426-13A, The Herman Järnhardt Foundation, The Foundation for Visually Impaired in Former Malmöhus län, and Crown Princess Margareta's Foundation for Visually Impaired. We would also like to thank all the participating doctors for their interest and collaboration in this project.

\section{Author details}

${ }^{1}$ Department of Clinical Sciences, Ophthalmology, Malmö, Lund University, Sweden. ²Department of Ophthalmology, Elblandklinikum Radebeul, Radebeul, Germany. ${ }^{3}$ Department of Ophthalmology, University of Dresden, Dresden, Germany.

\section{Authors' contributions}

The practical arrangements of the project and its implementation was carried out by SA with aid from AH and BB. SA performed the calculations of data and the statistical analyses in collaboration with BB. The manuscript was drafted by SA but $A H$ and BB, who designed the study, also contributed substantially with the work of the manuscript. The lecture in $\mathrm{ONH}$ assessment was planned and carried out by AGB who also drafted the lecture session of the manuscript. All authors read and approved the final manuscript.

\section{Competing interests}

The authors declare that they have no competing interests.

Received: 30 September 2010 Accepted: 19 May 2011

Published: 19 May 2011

\section{References}

1. Snydacker D: The Normal Optic Disc. Ophthalmoscopic and Photographic Studies. Am J Ophthalmol 1964, 58:958-964.

2. Read RM, Spaeth GL: The practical clinical appraisal of the optic disc in glaucoma: the natural history of cup progression and some specific disc-field correlations. Trans Am Acad Ophthalmol Otolaryngol 1974, 78(2): OP255-274.

3. Cher I, Robinson LP: 'Thinning' of the neural rim of the optic nerve-head. An altered state, providing a new ophthalmoscopic sign associated with characteristics of glaucoma. Trans Ophthalmol Soc U K 1973, 93(0):213-242.

4. Hitchings RA, Spaeth GL: The optic disc in glaucoma. I: Classification. Br J Ophthalmol 1976, 60(11):778-785.

5. Airaksinen PJ, Mustonen E, Alanko HI: Optic Disk Hemorrhages Precede Retinal Nerve-Fiber Layer Defects in Ocular Hypertension. Acta Ophthalmol 1981, 59(5):627-641.

6. Jonas JB, Gusek GC, Naumann GO: Optic disc morphometry in chronic primary open-angle glaucoma. I. Morphometric intrapapillary characteristics. Graefes Arch Clin Exp Ophthalmol 1988, 226(6):522-530.

7. Armaly MF: Genetic determination of cup/disc ratio of the optic nerve. Arch Ophthalmol 1967, 78(1):35-43.

8. Bengtsson B: The variation and covariation of cup and disc diameters. Acta Ophthalmol (Copenh) 1976, 54(6):804-818.

9. Heijl A, Molder $\mathrm{H}$ : Optic disc diameter influences the ability to detect glaucomatous disc damage. Acta Ophthalmol (Copenh) 1993, 71(1):122-129.

10. Jonas JB, Fernandez MC, Naumann GO: Glaucomatous optic nerve atrophy in small discs with low cup-to-disc ratios. Ophthalmology 1990, 97(9):1211-1215.

11. Correnti AJ, Wollstein G, Price LL, Schuman JS: Comparison of optic nerve head assessment with a digital stereoscopic camera (discam), scanning laser ophthalmoscopy, and stereophotography. Ophthalmology 2003, 110(8):1499-1505.

12. Deleon-Ortega JE, Arthur SN, McGwin G Jr, Xie A, Monheit BE, Girkin CA: Discrimination between glaucomatous and nonglaucomatous eyes using quantitative imaging devices and subjective optic nerve head assessment. Invest Ophthalmol Vis Sci 2006, 47(8):3374-3380.

13. Harper R, Radi N, Reeves BC, Fenerty C, Spencer AF, Batterbury M: Agreement between ophthalmologists and optometrists in optic disc assessment: training implications for glaucoma co-management. Graefes Arch Clin Exp Ophthalmol 2001, 239(5):342-350.

14. Morgan JE, Sheen NJ, North RV, Goyal R, Morgan S, Ansari E, Wild JM: Discrimination of glaucomatous optic neuropathy by digital stereoscopic analysis. Ophthalmology 2005, 112(5):855-862. 
15. Reus NJ, Lemij HG, Garway-Heath DF, Airaksinen PJ, Anton A, Bron AM, Faschinger C, Hollo G, lester M, Jonas JB, et al: Clinical Assessment of Stereoscopic Optic Disc Photographs for Glaucoma: The European Optic Disc Assessment Trial. Ophthalmology 2009.

16. Varma R, Steinmann WC, Scott IU: Expert agreement in evaluating the optic disc for glaucoma. Ophthalmology 1992, 99(2):215-221.

17. Wollstein G, Garway-Heath DF, Fontana L, Hitchings RA: Identifying early glaucomatous changes. Comparison between expert clinical assessment of optic disc photographs and confocal scanning ophthalmoscopy. Ophthalmology 2000, 107(12):2272-2277.

18. Gundersen KG, Heijl A, Bengtsson B: Age, gender, IOP, refraction and optic disc topography in normal eyes. A cross-sectional study using raster and scanning laser tomography. Acta Ophthalmol Scand 1998, 76(2):170-175.

19. Gundersen KG, Heijl A, Bengtsson B: Optic nerve head sector analysis recognizes glaucoma most effectively around disc poles. Acta Ophthalmol Scand 1999, 77(1):13-18.

20. Fingeret M, Medeiros FA, Susanna R Jr, Weinreb RN: Five rules to evaluate the optic disc and retinal nerve fiber layer for glaucoma. Optometry 2005, 76(11):661-668.

21. Altman DG: Practical Statistics for Medical Research. Chapman and Hall; 1991.

22. Margolis KL, Money BE, Kopietz LA, Rich EC: Physician recognition of ophthalmoscopic signs of open-angle glaucoma: effect of an educational program. J Gen Intern Med 1989, 4(4):296-299.

23. Sheen NJ, Morgan JE, Poulsen JL, North RV: Digital stereoscopic analysis of the optic disc: evaluation of a teaching program. Ophthalmology 2004, 111(10):1873-1879.

24. Stone RA, Ying GS, Pearson DJ, Bansal M, Puri M, Miller E, Alexander J, PiltzSeymour J, Nyberg W, Maguire MG, et al: Utility of digital stereo images for optic disc evaluation. Invest Ophthalmol Vis Sci 2010, 51(11):5667-5674.

25. George LD, Leverton C, Young S, Lusty J, Dunstan FD, Owens DR: Can digitised colour $35 \mathrm{~mm}$ transparencies be used to diagnose diabetic retinopathy? Diabet Med 1997, 14(11):970-973.

26. Rudnisky CJ, Tennant MT, Weis E, Ting A, Hinz BJ, Greve MD: Web-based grading of compressed stereoscopic digital photography versus standard slide film photography for the diagnosis of diabetic retinopathy. Ophthalmology 2007, 114(9):1748-1754.

27. Scholl HP, Dandekar SS, Peto T, Bunce C, Xing W, Jenkins S, Bird AC: What is lost by digitizing stereoscopic fundus color slides for macular grading in age-related maculopathy and degeneration? Ophthalmology 2004, 111(1):125-132.

28. van Leeuwen R, Chakravarthy U, Vingerling JR, Brussee C, Hooghart AJ, Mulder PG, de Jong PT: Grading of age-related maculopathy for epidemiological studies: is digital imaging as good as $35-\mathrm{mm}$ film? Ophthalmology 2003, 110(8):1540-1544.

Pre-publication history

The pre-publication history for this paper can be accessed here: http://www.biomedcentral.com/1471-2415/11/12/prepub

doi:10.1186/1471-2415-11-12

Cite this article as: Andersson et al.: The Effect of Education on the Assessment of Optic Nerve Head Photographs for the Glaucoma Diagnosis. BMC Ophthalmology 2011 11:12.

\section{Submit your next manuscript to BioMed Central and take full advantage of:}

- Convenient online submission

- Thorough peer review

- No space constraints or color figure charges

- Immediate publication on acceptance

- Inclusion in PubMed, CAS, Scopus and Google Scholar

- Research which is freely available for redistribution

Submit your manuscript at www.biomedcentral.com/submit
Biomed Central 